\title{
CONF-8706157--2
}

UCRL- 96832

PREPRINT

\section{TRANSPORT VEHICLE FOR MANNED MARS MISSIONS POWERED BY INERTIAL CONFINEMENT FUSION}

C. D. Orth, G. Kleln, J. Sercel, N. Hoffman, $K$. Murray, and F. Chang-Dlaz

This paper was prepared for submittal to AIAA/SAE/ASME/ASEE 23rd Joint Propulsion Conference

San Diego, Call fornia

June 29-July 2, 1987

June 26,1987

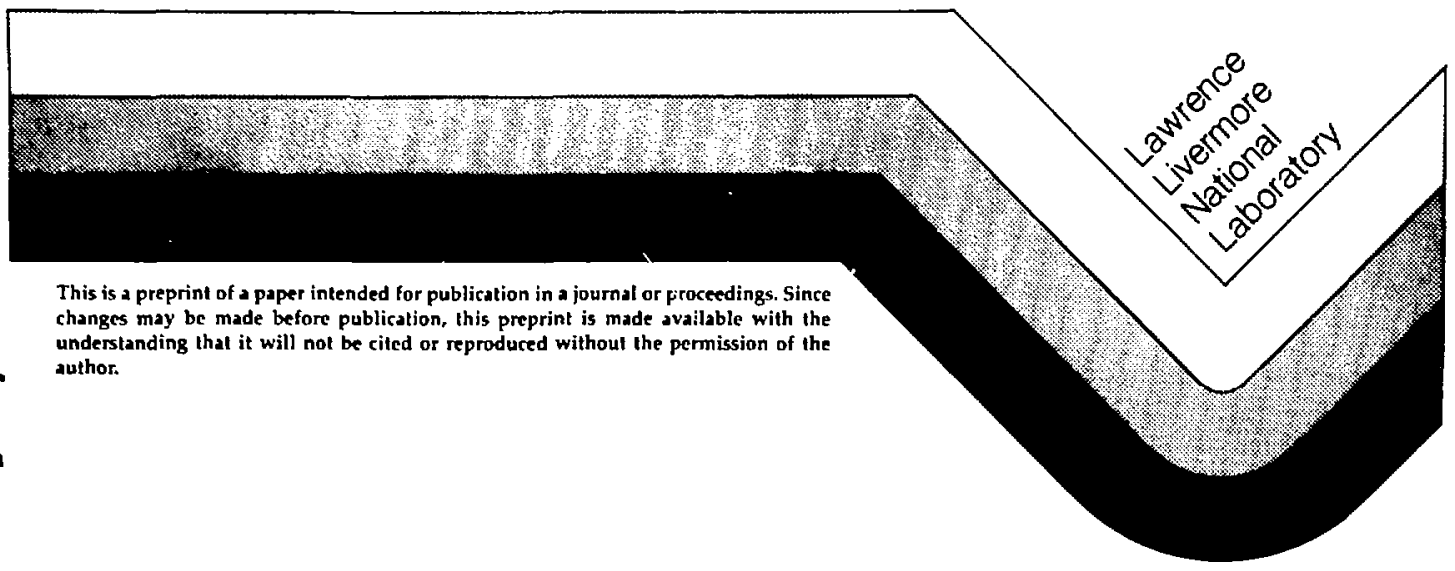


TRANSPORT VEHICLE FOR MANNED MARS MISSIONS

POWERED BY INERTIAL CONFINEMENT FUSION

Charles D. Orth

Lawrence Livermore National Laboratory, Livermore, CA

\author{
Gail Klein and Joel Sercel \\ Jet Propulsion Laboratory. Pasadena, CA \\ Nathan Hoffman and Kathy Murray \\ ETEC/Rocketdyne/Rockwe 11, Canoga Park, CA \\ Franklin Chang-Diaz \\ NASA, Johnson Space Center, Houston, ix \\ UCRL $\cdot-96832$ \\ DE87 012909
}

\title{
ABSTRACT
}

Inertial confinement fusion (ICF) is an ideal engine powar source for manned spacecraft to Mars because of its inherently high powe:-to-mass ratios and high specific impulses. We have produced a concept for a ehicle powered by ICF and utflizing a magnetic thrust chamber to avoid plasma thermalization with wall structures and the resultant degradation of specific impulse that are unavoidable with the use of mechanical thrust chambers. This vehicle is capable of 100-day manned Mars missions with a 100-metric-ton payload and a total vehicle launch mass near 6000 metric tons, based on advanced technology assumed to be available by A.D. 2020. Such short-duration missions minimize radiation exposures and physiological deterioration of astronauts.

\section{INTRODUCTION}

An inertial confinement fusion (ICF) microexplosion utilizing deuterium-tritium (DT) fuel releases up to $3.4 \times 10^{11} \mathrm{~J} / \mathrm{g}$ in the form of neutrons, $x$ rays, and plasma debris. Such huge specific energies afford very high power-to-mass ratios (ten to several hundred watts per gram) and very high specific impulses (tens of thousands of seconds). ICF is thus well suited as a engine power source for short-duration manned Mars missions, provided the high specific energy can be utilized without thermalization with wall structures in a mechanical thrust-chamber enclosure.

Thermalization can be avoided by using a magnetic thrust chamber, as originally proposed in 1972 by Hyde, Hood, and Nuckolls. 1 In 1983, Hyde 2 developed a complete concept of a pencil-shaped, laser-fusion-powered vehicle for interplanetary transport using pure-deuterium fuel; Hyde assumes a pellet gain of 1000 at a driver energy of $2 \mathrm{MJ}$. His thrust chamber incorporates a 16-T superconducting magnet to redirect the pellet debris, and operates at $100 \mathrm{~Hz}$ with a jet efficiency of $42 \%$ based on imperfect colilimation of the exhaust plume. 
We extended Hyde's concept by conducting a more complete and detailed systems study. Our objective was to specify a viable system concept for missions to Mars incorporating technology likely to be available by A.D. 2020. Our results, published el sewhere ${ }^{3}$ and summarized here, include an entirely new spacecraft concept called VISTA (vehicle for interplanetary space transport applications). VISTA is capable of manned Mars missions with a payload of 100 tons, a total vehicle launch mass near 6000 tons, and a total mission duration of roughly 100 days, including a stay on the planet of about 10 days. We emphasize that this concept depends on the development of the advanced technology assumed for many of the vehicle systems, including advanced laser drivers, very high pellet gain;, and advanced heat-pipe radiators. Note that, in this paper, "ton" means a metric ton $\left(10^{6} \mathrm{~g}\right)$.

\section{SPACECRAFT DESIGN CONCEPTS}

Figure 1 gives an artist's conception of the systems layout. The primary spacecraft structure is a cone. Crew systems are located at the rim of the cone, buried inside the propellant tanks for added radiation-exposure protection. A $13-m-r a d i u s, 300-k A / \mathrm{cm}^{2}$ warm-superconducting magnet generates a magnetic field that has a peak strength of about $12 \mathrm{~T}$ and that defines the boundaries of a thrust chamber. Pre-assembled pellets are filled enroute with liquid deuterium (D) and tritium (T) fuel, which are isotopes of hydrogen. The fuel pellets are surrounded by about $50 \mathrm{~g}$ of added material (expellant) and are accelerated, injected, and positioned in the thrust chamber at a repetition rate that is variable from zero up to about $30 \mathrm{~Hz}$. Beams from an excimer laser delivering about $5 \mathrm{MJ}$ of $0.5-\mu \mathrm{m}$ light with an efficlency of at least $6 \%$ (at $1000 \mathrm{~K}$ ) are focused on the pellet. The laser beams cause the pellet to implode and release up to $7500 \mathrm{MJ}$ in neutrons, $x$ rays, and plasma debris energy as the fusion reactions convert the pellet and the surrounding expellant into an expanding debris cloud.

Approximately one-fourth of the DT fusion energy is released as plasma debris kinetic energy. This plasma, being conductive, expands away from the pellet firing location until the bulk plasma pressure drops below the magnetic field pressure. The debris is then deflected by the magnet, which stores an energy that is at least 5 times the debris kinetic energy. The debris, which is cooling and decreasing in conductivity, leaves the thrust chamber in a limited solid angle, producing thrust and propelling the spacecraft with its blunt end forward. A small amount of debris leaks forward along the magnet axts and is considered below in the estimate of jet efficiency.

Note that VISTA obtains its thrust by converting the thermal energy from the fusion reactions into directed kinetic energy of the debris. The thrust can be varied by changing the engine repetition rate (or the expellant mass, or possibly even the pellet gain). The pellet gain (the ratio of the energy produced by the fusion reactions to the driver energy supplied to the pellet) can be as high as about 1500 for very advanced DT technologies (see below). Such gains allow the ICF engine to have a power-to-mass ratio of about $10 \mathrm{~W} / \mathrm{g}$.

VISTA's overall geometry is that of a $50^{\circ}$-half-angle cone. This shape is required to avoid massive radioactive shielding and to keep fusion neutrons (and $x$ rays) from striking and heating vehicle surfaces. The $50^{\circ}$ half angle maximizes jet efficiency, and is determined by selecting the optimum pellet 


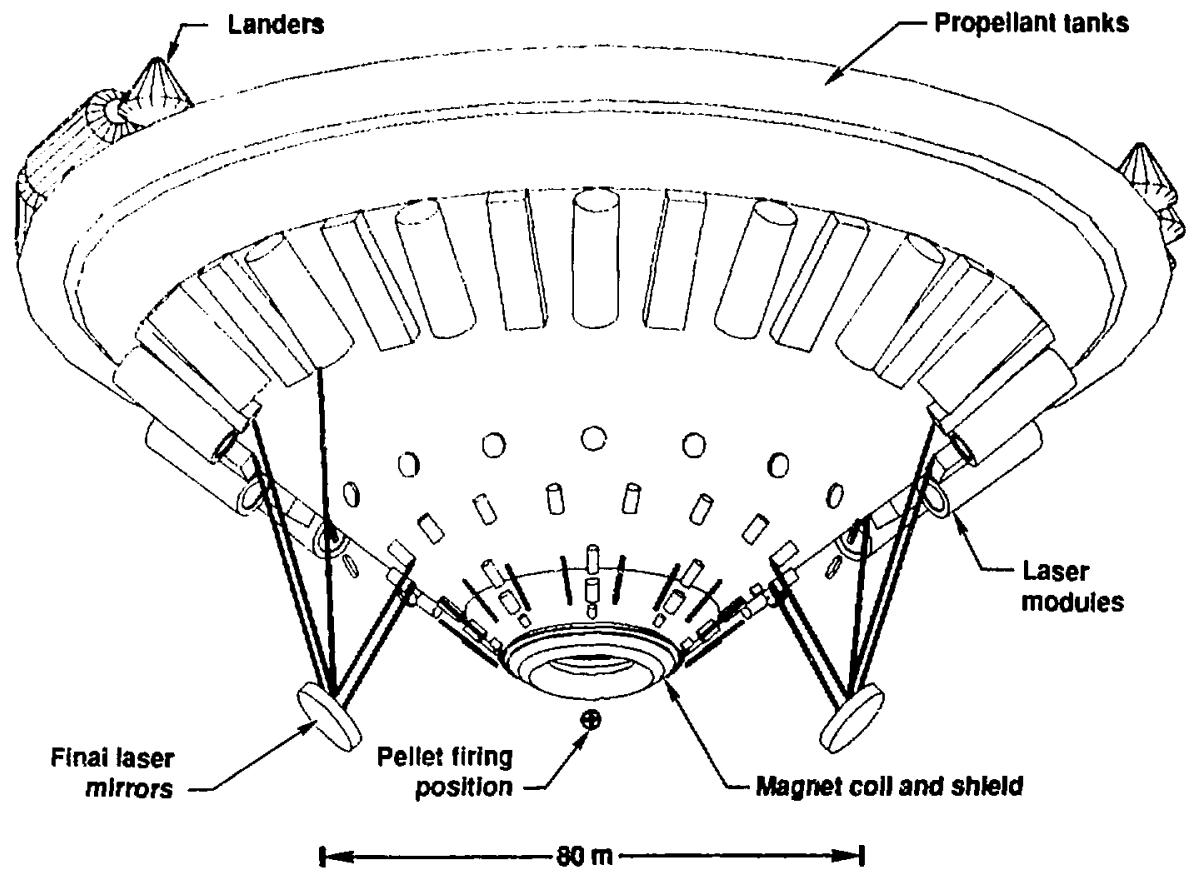

Figure 1. VISTA systems layout. Two final laser focusing mirrors are shown, but optional configurations incorporate multiple mirrors. 
firing position along the axis of the cone with respect to the plane of the magnet coil, in a manner similar to that done by Hyde.2

The conical shape is primarily a result of the use of DT fusion fuel. With $50 \mathrm{~g}$ of expellant per fusion pellet, about $60 \%$ of the energy released is in neutrons, whose initial energy is $14 \mathrm{MeV}$. To prevent neutron heating of the superconducting medium of the magnet coil, a 1.5-m-thick shield of liquid lithium is placed on the pellet side of the magnet coil to absorb all incident neutrons. The fraction of fusion neutrons and $x$ rays striking this shield depends on the minimum size of the magnet windings and on the distance of the coil from the pellet.

The overall scale of the thrust chamber is made large enough to avoid $x$-ray ablation of structures during an engine pulse that releases $7500 \mathrm{MJ}$. This requires that the coil shield be about $15 \mathrm{~m}$ from the pellet: the coll windings therefore subtend a fractional solid angle of $2 \%$ at the pellet. To allow for edge effects, we find that the coil shield must intercept about 3\% of the pellet neutrons and $x$ rays. The final laser turning mirrors and the pellet injector outlet port intercept an additional 1\%. The remaining $96 \%$ of the neutrons and $x$ rays stream out isotropically into space, and do not strike or heat vehicle surfaces.

The coil shield required for the magnet thus casts a conical shadow devoid of pellet emissions. We therefore chose the VISTA geometry to be a cone with its apex at the pellet, and placed all vehicle systems in the shadow of the coil shleld. This structure is not only mechanically rigid, but is stable during steering maneuvers. The cone itself serves both as a structural support for attachment of vehicle systems (laser drivers, power conditioners, etc.) and as a surface for radiating waste heat. In fact, the core heat pipes are designed to give the cone its structural support; suitable stiffeners are added for local attachments, while the branch heat pipes form the main conical surface.

This geometry has two disadvantages. First, it is not as effective as planar geometries in utilizing both sides of its surface as radiating surface area, because the interior conical surface partially views itself. Second, the conical geometry is not as conducive to protection from micrometeoroids as a plane moving with one of its edges forward, as in Hyde's scheme. 2 Fore and aft micrometeoroid shields (not shown in Fig. I---see Ref. 3) must therefore be included to protect the main conical surface in both acceleration and deceleration orientations relative to vehicle motion.

\section{PELLET SYSTEMS}

Reference 3 gives detailed analyses of the pellet systems and gains. Even though terrestrial power reactors require pellets with gains of only 50 to 200 for current laser-driver concepts, we assume that very advanced pellet technology will permit gains up to 1500. Such high gains are possible according to the Meyer-ter-Vehn analytic model, 4 which in essence shows that pellet gain can be as high as $G=877 E_{d} / 3$, where the driver energy $E_{d}$ is in megajoules; such gains, however, should be regarded as speculative.

About $44 \mathrm{mg}$ of DT fuel are needed to produce $7500 \mathrm{MJ}$ of fusion output (5 MJ input energy at gain 1500) if the fusion burn is $50 \%$ efficient. Each 
pellet therefore contains $26.5 \mathrm{mg}$ of tritium. A 100-day Mars mission will require 35 to 40 tons of DT fuel, which will include 20 to 25 tons or tritium. This tritium generates $0.33 \mathrm{~W} / \mathrm{g}$ of radioactive decay heat, which means 8.3 MH for all of the tritium. It is therefore impossible to keep the tritium at cryogenic temperatures; it must be stored in a tank that will reach its own elevated equilibrium temperature as the decay heat is radiated to space. The deuterium fuel and hydrogen expellant, however, can be stored cryogenically with modest tankage and refrigeration. Reference 3 discusses other types of expellant material that can be used.

There are several reasons why VISTA uses DT fuel rather than advanced fuels such as $D D$ or $D^{3} \mathrm{He}$, even though tritium presents difficulties because of its radioactivity. For VISTA, the important quantity is the product of the pellet gain and the fraction of fusion output in debris energy. Although the advanced fuels have much higher debris fractions, their gains are lower by a factor of about 6 . As a result, the product of gain and debris fraction is slightly lower for the advanced fuels than for DT, suggesting that advanced fuels would never outperform DT. It is possible, however, for advanced fuels to outperform DT at gains above about 200 by choosing different operating conditions for the different fuels. However, the added performance is insignificant (the trip time is on the order of few percent shorter).

In addition, the pellet technology for the advanced fuels does not now exist, and pellet gains above 200 for advanced fuels represent extremely advanced pellet technology, and therefore very far term. Besides, the required quantities of $3 \mathrm{He}$ are not available on earth, so the use of $3 \mathrm{He}$ would necessitate mining the lunar surface and/or the Jovian atmosphere. For these reasons, we chose DT as the best fuel for the near term.

\section{DRIVER SYSTEMS}

The laser driver is modular, both for redundancy and to make it possible to assemble the final beams from smaller-diameter beams without exceeding the maximum allowable fluence on any optical component. Considerable development would be needed to make any driver concept currently being developed for terrestrial use applicable for use in a space propulsion system. The concept most likely to achieve high efficiency, low mass, and high operating temperature (to minimize radiator mass) seems to be some form of excimer laser. He therefore chose an excimer laser operating at $1000 \mathrm{~K}$ and at about $0.5 \mu \mathrm{m}$ waveiength, with an efficiency of $6 \%$ for a radiating temperature of $900 \mathrm{~K}$, and a mass of 300 tons. This system must operate reliably for $10^{8}$ rapetitions.

Such a driver concept repiesents an extrapolation of existing technology in a number of ways. Foremost, no terrestrial concept with acceptable total mass can fire $10^{8}$ times witheut hardware changes (KrF foils, light-ion diodes, etc.). Other extrapolations pertain to the lifetimes and damage thresholds for laser optics and coatings operating at sub-micron wavelengths, which are not well knowl (especially for materials subjected to high neutron fluences). Also, very high beam quality (uniformity) is required to focus the light from the final turning mirrors onto the pellet, and this beam quality is probably beyond current technology. Even the energy and efficiency estimates are extrapolations of existing technology. Nevertheless, the terrestrial ICF 
program has similar end requirements in nearly all areas, so it is highly likely that the required extrapolations will be realized before A.0. 2020 .

\section{THRUST CHAMBER}

We do not fully understand the plasma processes that are vital for effective thrust-chamber operation. Expansion of the pellet debris and Interaction of the debris with the magnetic field occur on time scales on the order of tens to hundreds of microseconds. We have assumed that the plasma would maintain enough conductivity to resist significant magnetic field penetration during its transit through the thrust chamber. We have also assumed that the exhaust would decouple at high beta (the ratio of particle pressure to magnetic field pressu'e). so that debris particles would not spiral around the field lines and return to strlke spacecraft components. Studies are under way to determine the validity of these assumptions, and whether jet efficiency would be degraded by plasma field penetration. If it is necessary to increase jet effictency by further restricting the solid angle of exhaust exit, the plume can be shaped by employing other magnets, but not without additional dry mass and structural complexity.

We estimate that the thrust chamber is about $60 \%$ efficient in converting the mass flow into directed exhaust momentum. [In obtaining this estimate, we account for the non-colinearity of the exiting debris particles, for a small drag generated in the thrust charber by the nonzero resistivity of the cooling plasma (which allows magnetic field penetration of the plasma, and hence difficulties in decoupling the exhaust from the magnetic field), and for a smali loss of debris forward along the magnet axis.] Squaring this figure, we find that VISTA is $36 \%$ efficient in converting debris energy intu jet power. Multiplying the debris exhaust speed of $3 \times 10^{5} \mathrm{~m} / \mathrm{s}$ by the $60 \%$ momentum efficiency, we calculate VISTA's effective specific impulse to be near $20,000 \mathrm{~s}$. This specific impulse is possible only because the debris particles do not contact any surrounding structures.

\section{PONER SYSTEHS}

The power systems must be capable of supplying approximately 1 HW of auxiliary dc power, and up to $2.5 \mathrm{GW}$ in pulsed power to run the inefficient laser driver (driver input pulses are $600 \mathrm{kV}$ for 0.4 us at typically I to $30 \mathrm{~Hz}$, each pulse supplying $83 \mathrm{~mJ}$ ). This power must come from the fusion process. Two types of power conversion systems have been considered: (1) a Rankine cycle utilizing waste neutron heat deposited in the liquid lithium that forms the magnet coll shield, and (2) an inductor pickup coji2 that generates an emf through magnetic induction when the magnetic field lines are compressed by the expanding peilet debris and pass through the inductor coil "windings."

The Rankine option must be only $20 \%$ efficient for minimum mass per unit power (as opposed to maximum efficiency), and operates in a dc (not a pulsed) mode. Its use requires lateral extension of the coil shield into a lithium "blanket" to accept tens of percent of the neutron energy instead of the $3 \%$ accepted by the shield. As a result, its 1000 tons would essentially double the vehicle dry mass. The Rankine system is therefore not competitive. 3 
The inductor would operate at the same frequency as the driver, which is the main power demand, so an advanced power system can be designed that compresses the inductor pulse to the $0.4-\mu \mathrm{s}$ pulse duration needed by the driver, without going through an intermediate dc stage. A fallback option utilizes rectification of the inductor pulses, with capacitive storage. 3

With either inductor option, the electrical energy is extracted from the debris energy, but without significant reduction in vehicle thrust. Because the inefficiency in the engine arises primarily from the relatively large solid angle of emission of the debris trajectories exiting the thrust chamber (and not simply from loss of debris energy), the ratio of the inductor power extracted from the debris and the power in the debris traveling through the thrust chamber is the inverse of the product of the pellet gain, the driver efficiency, and the fraction of fusion energy in debris. For VISTA, this ratio is about $4 \%$ for a gain of 1500 .

The inductor subsystem itself adds essentially no mass, because the interior surface of the coll shleld can serve as the coll "windings." We have added 25 tons for all inductor systems, including the power-conditioning subsystems. If the fallback capacitive inductor power-conditioning option is exercised, however, we would have to add 200 to 400 tons. Such a mass would restrict vehicle performance.

The 1 MW of auxillary pawer (for crew systems and housekeeping, refrigeration subsystems, pellet filling and injection subsystenls, reaction control, communications, etc.) is easily extracted from the main power system. A separate 100-kW fission reactor for engine startup is also required to melt the lithium in the coll shield and to supply the $83 \mathrm{MJ}$ necessary to fire the first driver pulse.

\section{THERMAL SYSTEMS}

Heat-pipe radiators are used to remove waste heat arising from inefficiencies in the driver and power systems, and from pellet-emission depositions in the final laser mirrors, the pellet injector port, and the coil shield (with the liquid lithium acting as the transfer fluid). inermal control (refrigeration) is required to maintain the temperature of the superconductor for the magnet and the temperature of the propellant tanks, and to liquefy tritium.

The design of the heat-pipe radiators affects vehicle performance unless their mass is small compared with other vehicle dry mass. Radiator design begins to affect performance above about $0.1 \mathrm{~kg} / \mathrm{kWt}$ at $1000 \mathrm{~K}$. For results presented here, we hava assumed the equivalent of $0.07 \mathrm{~kg} / \mathrm{kWt}$ at $1000 \mathrm{~K}$. Current technology is $0.15 \mathrm{~kg} / \mathrm{kWt}$ at $1000 \mathrm{~K}$, and this would have to be increased to perhaps $0.2 \mathrm{~kg} / \mathrm{kWt}$ for VISTA because the VISTA radiator surface is also a structural load-bearing surface that needs added strength. The radiator design is thus one area in which VISTA is dependent on future technological advance.

Up to $2400 \mathrm{MW}$ must be radiated at $900 \mathrm{~K}$ for the driver operating at $1000 \mathrm{~K}$, and up to $10,000 \mathrm{MW}$ must be radiated at $1500 \mathrm{~K}$ for the coil shield. The fore and aft micrometeoroid shields allow thin, double-walled construction of the branch heat pipes to meet the $0.07 \mathrm{~kg} / \mathrm{kWt}$ specification at these power levels. We designed the structural layout of the branch radiator assemblies 
in the conical mesh of stronger core heat pipes using the NASTRAN and other computer codes. Local stiffening is provided as needed in the shell to support mounted components and to provide structural attachment points. Peak acceleration is less than $0.02 \mathrm{~g}$, and stresses are typically less than 3 kpsi.

\section{RADIATION HAZARDS}

The radioactivity of the tritium fuel presents a hazard during boost into orbit and during onboard pellet filling and transfer, and requires storage of the tritium in a temperature-elevated tank because of its decay waste heat of $0.33 \mathrm{~W} / \mathrm{g}$. These hazards are presumed to be manageable.

The crew can be adequately shielded from solar flares and cosmic rays (and some stray fusion neutrons) by placing the crew systems inside the expellant tanks and by surrounding them with mass associated with other vehicle systems. However, operation of VISTA does present a hazard for unshielded personnel in nearby spacecraft or in a space station, if VISTA is initialiy at rest relative to these vehicles. Each fusion pulse releases over $10^{20}$ neutrons, so at peak engine operation, there is a hazard for unshielded nearby personnel for several hours until VISTA has moved off several thousand kllometers. This hazard would of course be mitigated by providing shielding for the personnel in these other spacecraft.

\section{MISSION PERFORMANCE}

Table 1 shows a typical power flow for VISTA, and Table 2 lists the masses and other parameters for the various systems. Note that VISTA, at about 6000 tons, is a very heavy vehlcle, requiring the equivalent of 30 trips of NASA's heavy-lift launch vehicle for assembly in orbit. Nevertheless, it serves as a fast transport to Mars, with round-trip travel times near 100 days (with coasts), including about 10 days on the planet. Typical vehicle coast velocitles are 40 to $60 \mathrm{~km} / \mathrm{s}$. Such short durations reduce the leukemia and otiver cancer hazards for astronauts while they are not protected by vehicle shlelding, which must be equivalent to about 1-m-thickness of water. Short missions also minimize astronaut calcium insses. If mission durations longer than 100 days would be acceptable, lower vehicle launch masses could be employed. Reference 3 documents other performance results, and a parametric analysis.

If radiator or driver technology develops even faster than we anticipate, vehicle dry mass could be lower, and performance could improve and/or vehicle launch mass could be much lower. Wtth the current estimates of technology advances, the flight duration for VISTA is at least a factor of 2 or 3 shorter than with nuclear electric propulsion, and is roughly a factor of 10 shorter than with chemical rockets, for mimimum-mass configurations. Such performance is dependent on the development of very high pellet galns.

\section{ACKNONLEDGMENTS}

We gratefully acknowledge advice and assistance from Rod Hyde at LLNL; from Carl Sauer, Andrey Sergeyevsky, Stan Krauthamer. Hoppy Price, Alok Chatterjee, Katie Barhydt, and Jayant Sharma at JPL; and from Tien-Fang Yang 
Table 1. Approximate power flow (MW) in VISTA at $5 \mathrm{~Hz}$ (driver output energy $5 \mathrm{MJ}$, pellet gain 1500). For $30 \mathrm{~Hz}$, multiply values by 6 .

Driver

Input

Radiators

Output

Pellet

Input

Output

Debris (1/4 total)

25

37500

9400

Thrust chamber

Direct loss to space

(neutrons and $x$ rays)

27000

Jet power

3380

Unused debris power

4900

Radiated power

1800

Electrical inductor power output 420 
Table 2. Masses and other parameters of VISTA vehicle systems.

\begin{tabular}{|c|c|c|}
\hline $\begin{array}{l}\text { river } \\
\text { Energy output (MJ) } \\
\text { Efficiency (1000 K) ( }(Z) \\
\text { Radiator temperature }(K)\end{array}$ & $\begin{array}{l}5 \\
6 \\
900\end{array}$ & \\
\hline $\begin{array}{l}\text { Pellet } \\
\text { Fuel } \\
\text { Gain } \\
\text { Expellant mass per pellet }(g)\end{array}$ & $\begin{array}{l}\text { DT } \\
\leq 1500 \\
50\end{array}$ & \\
\hline $\begin{array}{l}\text { Engine } \\
\text { Effactive speciflc impulse (s) } \\
\text { Power per unit mass }(\mathrm{W} / \mathrm{g}) \\
\text { Mass fiow rate at } 30 \mathrm{~Hz}(\mathrm{~kg} / \mathrm{s}) \\
\text { Thrust at } 30 \mathrm{~Hz}(\mathrm{~N}) \\
\text { Jet power at } 30 \mathrm{~Hz}(\mathrm{MW}) \\
\text { Jet effictency }(\mathrm{H})\end{array}$ & $\begin{array}{l}17000 \\
0.6 \times \text { repetition } \\
1.5 \times 105 \\
2.4 \times 10^{4} \\
2.0 \times 10^{4} \\
36\end{array}$ & rate \\
\hline ate system masses at & tons) & \\
\hline $\begin{array}{l}\text { Payload } \\
\text { Crew shield } \\
\text { Propellant } \\
\text { Fuel } \\
\text { Expel lant } \\
\text { Refrigeration/11 quefaction } \\
\text { Tankage }\end{array}$ & $\begin{array}{r}40 \\
4100 \\
50 \\
200\end{array}$ & $\begin{array}{r}100 \\
140 \\
4 \quad 390\end{array}$ \\
\hline Driver & & 500 \\
\hline $\begin{array}{l}\text { Equipment } \\
\text { Radiators }\end{array}$ & $\begin{array}{l}300 \\
200\end{array}$ & \\
\hline $\begin{array}{l}\text { Thrust chamber } \\
\text { Coll } \\
\text { Coil shield } \\
\text { Radiators } \\
\text { Structure and equipment }\end{array}$ & $\begin{array}{r}20 \\
100 \\
330 \\
25\end{array}$ & 475 \\
\hline $\begin{array}{l}\text { Startup reactor } \\
\text { Power systems } \\
\text { Misc. structure and radiator shiel }\end{array}$ & & $\begin{array}{r}5 \\
90 \\
100\end{array}$ \\
\hline $\begin{array}{l}\text { Total } \\
\text { Dry mass } \\
\text { Propellant }\end{array}$ & $\begin{array}{l}1660 \\
4140\end{array}$ & 5800 \\
\hline
\end{tabular}


at MIT. Hork performed under the auspices of the U. S. Department of Energy by the Lawrence Livermore National Laboratory under contract number W-7405-Eng-48, and under the auspices of the National Aeronautics and Space Administration by the Jet Propulsion Laboratory, California Institute of Technology.

\section{REFERENCES}

1. R. Hyde, L. Hood, and J. Nuckolls, "Prospects for Rocket Propulsion with Laser-Induced Fusion Microexplosions," Lawrence Livermore National Laboratory, Livermore, Cal1f., UCRL-74218-Rev. 2 (1972); also avallable from Amerlcan Institute of keronautics and Astronautics, $555 \mathrm{~W}$. 57th St., New York, N.Y. 10019, AIAA Paper No. 72-1063 (1972).

2. R. A. Hyde, "A Laser Fusion Rocket for Interplanetary Propulston," Lawrence Livermore National Laboratory, Livermore, Cal if., UCRL-88857 (1983): presented at Conference 34. International Astronautical Federation (Budapest, Hungary, October 10-17, 1983).

3. C. D. Orth, G. Klein, J. Sercel, N. Hoffman, K. Murray, and F. Chang-Diaz, "VISTA: A Vehtcle for Interplanetary Space Transport Applications Powered by Inertial Confinement Fusion," Lawrence Livermore National Laboratory, Livermore, Calif., UCRL-53802 (to be published).

4. M. D. Rosen, J. D. Lind1, and A. R. Thiessen, "Simple Models of High-Gain Targets--Comparisons and Generalizations," in Laser Program Annual Report 83, Lawrence Livermore National Laboratory, Livermore, Calif., UCRL-50021-83 (1984), pp. 3-5 to 3-9.

\section{DISCLAIMER}

This report was prepared as an account of work sponsored by an azency of the United States Government. Neither the United States Government nor any agency thereof, nor any of their employees, makes any warranty, express or implied, or asumes any legal liability or responsibility for the accuracy, completeness, or usefulness of any information, apparatus, product, or process discloeed, or represents that its use would not infringe privately owned rights. Reference herein to any specific commercial product, process, or service by trade name, trademark, manufacturer, or otherwise does not necessarily constitute or imply its endorsement, recommendation, or favoring by the United States Government or any agency thereof. The views and opinions of authors expresed herein do not necessarily state or reflect those of the United States Government or any agency thereof. 